\title{
Algoritmos de Alocação Dinâmica de Largura de Banda para Redes de Acesso TDM/WDM EPON
}

\author{
Carmen C. Arbieto e Amílcar C. César
}

\begin{abstract}
Resumo- Algoritmos de alocação dinâmica de largura de banda para redes de acesso Ethernet passive optical network (EPON) são investigados neste artigo. Os algoritmos são baseados na técnica conhecida por interrogação intercalada com ciclos de tempos adaptativos (IPACT) e operam em esquema híbrido TDM/WDM. Esta abordagem permite atualização gradativa de técnica TDM para WDM, ampliando a largura de banda disponível. $O$ suporte a classes de serviço também é integrado ao esquema. Os resultados obtidos por meio de simulações mostraram bom desempenho do esquema TDM/WDM IPACT, atestando sua viabilidade.
\end{abstract}

Palavras-Chave - Passive optical network (PON), Ethernet PON, IPACT, WDM PON, alocação dinâmica de largura de banda, classes de serviços.

Abstract- This paper relates algorithms for dynamic bandwidth assignment for Ethernet passive optical network (EPON). Algorithms are based on IPACT and employ TDM/WDM scheme. The approach allows gradual migration from all TDM to all WDM EPON architectures, increasing the bandwidth available. Support to classes of service is also added to the scheme. Results obtained from computer simulations attest the viability of the approach.

Index Terms - Passive optical network (PON), Ethernet PON, IPACT, WDM PON, dynamic bandwidth assignment, classes of services.

\section{INTRODUÇÃO}

As redes de acesso PON (passive optical network) têm se mostrado alternativa viável para superar as limitações das tecnologias x-DSL (digital subscriber line) e CM (cable modem), que se tornaram gargalo na última milha [1]. Fazendo uso da largura de banda disponível na fibra óptica, elas se capacitam para dar suporte ao aumento do tráfego e ao oferecimento de serviços como voz sobre IP (Internet protocol), vídeo sob demanda, televisão de alta definição, videoconferência e dados.

De acordo com o protocolo que utilizam, as redes PON são classificadas em APON (ATM PON), EPON (Ethernet PON) e Gigabit PON (generic framing protocol-GFP) [2][3]. Apesar das vantagens dos vários protocolos, o padrão Ethernet tem se consagrado pelo uso generalizado como preferência em vários tipos de redes, incluindo as de acesso, padrão EPON.

A EPON apresenta vantagens como "escalabilidade"

Carmen C. Arbieto, carbieto@sel.eesc.usp.br, Amílcar C. César, amilcar@sel.eesc.usp.br, Universidade de São Paulo, EESC, Depto. Eng. Elétrica, Avenida Trabalhadora São-carlense, 400, 13566-590 São Carlos, SP, Brasil

Pesquisa parcialmente financiada pelo CNPq e FAPESP (Projeto TidiaKyaTera, proc. 03/08269-7). (scalability), manutenção simples e uso de equipamentos de baixo custo [4]. Novos critérios de QoS (quality of service) tornaram as EPONs capazes de suportar voz, dados e vídeo [1].

A padronização das redes EPON é realizada pelo grupo de trabalho "IEEE 802.3ah Ethernet na primeira milha". Este grupo especificou o protocolo MPCP (multipoint control protocol) para o acesso ao meio utilizando o esquema TDM (time division multiplexing). O MPCP fornece uma infra-estrutura de sinalização para coordenar a transmissão da informação entre as ONUs (optical network unit) e o OLT (optical line terminal).

Para gerenciar a largura de banda, o algoritmo de alocação deste recurso deve realizar o controle de acesso ao meio com base no MPCP, de maneira eficiente e dando suporte a vários tipos de serviços [5]. Entretanto, este algoritmo foi considerado fora do escopo de trabalho do grupo IEEE 802.3ah, permitindo que seja desenvolvido pelos fornecedores [5], [6].

Sendo assim, vários algoritmos de alocação de largura de banda têm sido propostos na literatura, utilizando o esquema TDM para EPON [1], [7], [8]. Dentre eles, o algoritmo DBA (dynamic bandwidth allocation), denominado interrogação intercalada com ciclos de tempos adaptativos (IPACT) [8], tem recebido considerável atenção, porque faz eficiente utilização da capacidade do canal [9]-[11]. Todos estes algoritmos foram elaborados para operar com taxa de 1 Gbps, segundo o especificado pelo IEEE 802.3ah, suportando de 16 a 64 ONUs. Por conseguinte, cada ONU poderá dispor de largura de banda mínima entre 15 Mbps e 60 Mbps. Em face do aumento do número de usuários e dos serviços banda larga, inevitavelmente, aquele limite terá que ser ampliado.

Uma alternativa para ampliar a largura de banda é utilizar a técnica WDM (wavelength division multipexing) [9], [12]. Entretanto, a implementação de rede de acesso com ONUs que operam somente com técnica WDM pode ser de alto custo, mesmo considerando todas as suas vantagens. Para superar esta dificuldade, foi proposta uma extensão do protocolo MPCP para permitir a migração do cenário TDM para o WDM de forma gradativa, segundo a demanda de novos usuários e as considerações econômicas. Esta extensão permite que a EPON opere no OLT e nas ONUs com arquiteturas arbitrárias [10], [11]. Assim, o esquema EPON TDM pode operar normalmente se algumas ONUs são atualizadas para WDM, segundo os requisitos, mantendo a mesma taxa de bits em cada canal, tanto para a transmissão upstream quanto para a downstream. A atualização de todas as ONUs para WDM culmina em um sistema WDM PON. 
Em [11], seus autores relataram a simulação da EPON utilizando duas políticas numa técnica híbrida TDM/WDM, denominado WDM-IPACT. Porém, nas suas simulações todas as ONUs são WDM.

Neste trabalho, simulamos uma arquitetura EPON TDM/WDM, utilizando um algoritmo modificado a partir esquema WDM IPACT proposto em [10]. Consideramos a EPON constituídas por três grupos de ONUs: (1) ONUs que operam em esquema TDM com um único $\lambda$ (não-WDM); (2) ONUs implementadas com um conjunto de transceptores fixos (WDM); (3) ONUs com transceptores sintonizáveis (WDM). Os dois últimos grupos são de ONUs atualizadas para realizar o acesso múltiplo WDM. A largura de banda mínima garantida das ONUs não-WDM pode ser variada segundo o número de ONUs atualizadas para operar com WDM. Além disso, integraremos o suporte a diferentes classes de serviço ao algoritmo proposto. Utilizaremos um esquema otimizado do algoritmo de suporte a diferentes classes especificado em IEEE 802.1D, proposto em [7] e denominado crédito CBR (constant bit rate). Portanto, avaliaremos o desempenho de algoritmo proposto, que denominaremos TDM/WDM IPACT, operando com três tipos de ONUs, primeiro atendendo somente um tipo de tráfego e posteriormente atendendo tráfego diferenciado. Os resultados numéricos mostram a utilidade da abordagem proposta.

\section{ARQUITETURA DA REDE}

Tipicamente, a EPON apresenta uma topologia em árvore e utiliza um comprimento de onda $(\lambda)$ para a transmissão upstream e outro para a transmissão downstream. Nesta topologia, o OLT conecta $N$ ONUs utilizando divisores/combinadores passivos. O OLT está localizado na central, interligando a rede de acesso com a rede metropolitana e administrando a transmissão das ONUs. A ONU está localizada no lado do assinante e pode atender assinantes residenciais, empresariais (fiber to the home or building - FTTH ou FTTB) ou vários assinantes (fiber to the cabine - FTTC e FTTCurb), proporcionando oferecimento de serviços de voz, vídeo e dados.

As propriedades direcionais do divisor/combinador óptico permitem que na direção downstream o OLT envie o sinal por difusão (broadcast) às ONUs, como é ilustrado na Fig. 1, sendo recebido pela ONU de destino de acordo com seu endereço MAC (media access control).

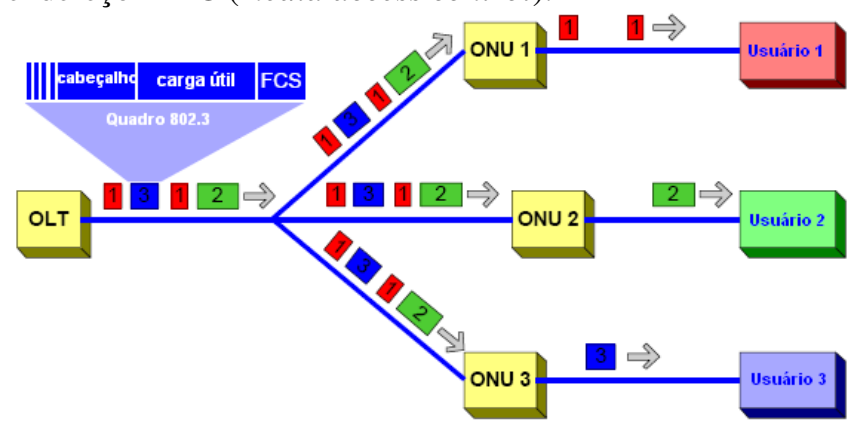

Fig. 1. Tráfego na direção downstream na EPON [13].

Na direção upstream as ONUs compartilham o canal para a transmissão. A ONU armazena em buffer a informação proveniente dos usuários até que possa realizar a transmissão da informação ao OLT, como está ilustrado na Fig. 2. As distâncias entre OLT e ONUs variam em trechos de 0 a $20 \mathrm{~km}$ e, portanto, o tempo de ida-e-volta (RTT) é diferente para cada ONU.

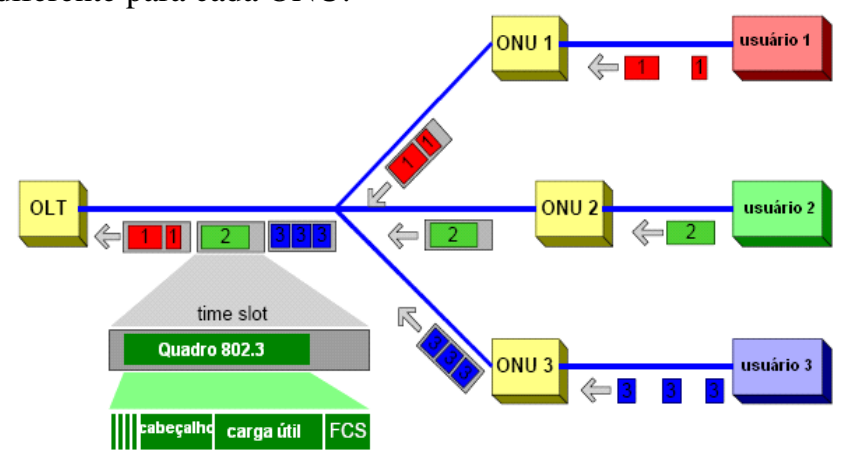

Fig. 2. Tráfego na direção upstream na EPON [13].

\section{Algoritmo DBA E Algoritmo De Suporte A DIFERENTES CLASSES DE SERVIÇO}

\section{A. Algoritmo IPACT}

O algoritmo IPACT é um esquema de alocação dinâmica de largura de banda para rede EPON [8]. Este algoritmo está centralizado no modulo DBA do OLT, encarregando-se de programar as transmissões e alocar a largura de banda eficientemente. O mecanismo de operação do IPACT é mostrado em exemplo (Fig. 3). O OLT envia a permissão (6000 bytes) à ONU1 e ela ao receber inicia imediatamente sua transmissão, adicionando no final seu pedido (700 bytes) para o próximo ciclo. Posteriormente, envia a permissão (3200 bytes) para a ONU2, antes de terminar a transmissão a ONU1. A operação é programada em função ao tempo de ida e volta à ONU. Finalmente, enquanto está recebendo a transmissão da ONU1, envia a permissão (1800 bytes) para a ONU3 (interrogação intercalada). As transmissões chegam ao OLT mantendo um intervalo de tempo entre elas, chamado tempo de guarda. Assim, o OLT é encarregado de manter o sincronismo do sistema. Aloca o timeslot solicitado à $\mathrm{ONU}$, de forma que ele não seja maior que o tamanho máximo permitido, para evitar a monopolização do canal. No IPACT, as ONUs não precisam realizar o sincronismo. Portanto, neste trabalho o IPACT foi modificado para as ONUs fazerem parte do sincronismo segundo o protocolo MPCP, especificado no padrão IEEE 802.3ah.

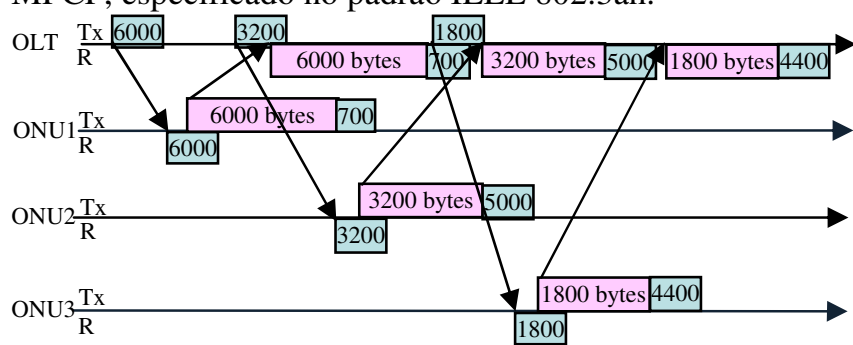

Fig. 3. Sondagem intercalada no IPACT.

\section{B. Algoritmo de Suporte a Classes de Serviço}

O desempenho de uma rede baseada em pacotes pode ser convenientemente caracterizado por meio de vários parâmetros, como a largura de banda, o atraso de quadro (latência), a variação do atraso (jitter) e a probabilidade de perda de quadros. O quadro é um conjunto de dados de nível mais baixo, gerados na camada de enlace do modelo OSI. 
Um pacote é divido em vários quadros. A QoS numa rede refere-se à habilidade em estabelecer limites de operação em alguns ou em todos aqueles parâmetros para uma determinada conexão.

O esquema DBA IPACT tem sido combinado com a programação de prioridade e o esquema denominado crédito CBR apresenta melhor desempenho [7]. Este esquema estabelece mecanismos para a programação de prioridades e o enfileiramento prioritário, realizados nas ONUs, listados a seguir.

\section{1) Programação de Prioridades}

A ONU realiza a programação dos quadros que serão transmitidos no timeslot atribuído da seguinte forma. Serão transmitidos os quadros de uma determinada fila de prioridade sempre e quando as filas de prioridades superiores estiverem vazias (esquema especificado em IEEE 802.1D). Porém, no início da transmissão, esta política é aplicada a todos os quadros que tenham chegado à $\mathrm{ONU}$ antes do instante da solicitação, conforme mostra a Fig. 4.

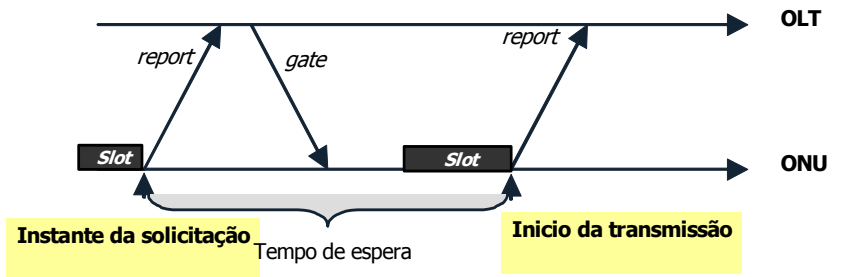

Fig. 4. Processo de envio da mensagem report e o início da transmissão no timeslot atribuído.

Adicionalmente, o OLT estima os quadros de prioridade alta que devem chegar à ONU no tempo de espera, adicionando-o ao timeslot que será alocado.

\section{2) Enfileiramento Prioritário}

O enfileiramento prioritário classifica o tráfego que chega à ONU e cada classe é armazenada em sua respectiva fila de prioridade. Para o enfileiramento é utilizada a política de se um quadro de prioridade alta encontra o buffer cheio, a ONU deslocará os quadros de prioridade baixa. Entretanto, se um quadro de prioridade baixa encontra o buffer cheio, o quadro será descartado. Todas as filas compartilham o mesmo buffer.

\section{Algoritmo TDM/WDM IPACT}

Em [10], [11] foi proposta uma extensão do protocolo MPCP, adicionando novos campos e mensagens de controle que permitem ao OLT conhecer o tipo de ONU que está sendo registrada. Se for WDM, a ONU terá que informar o tipo de transceptor que utiliza e os $\lambda$ s de operação. Se o transceptor é sintonizável informará o tempo de sintonização do transceptor. Estas funcionalidades, implementadas no OLT, permitirão a atualização evolutiva da EPON, que utiliza o esquema TDM, para uma arquitetura WDM.

As ONUs WDM podem ser dos tipos: (1) O OLT está implementado com um conjunto de receptores e laser fixos; (2) As ONUs, igualmente, podem estar equipadas por um conjunto de receptores e lasers fixos ou por receptores e lasers sintonizáveis.

\section{1) $T D M / W D M ~ I P A C T$}

Neste artigo, modificamos o algoritmo que implementa um esquema WDM proposto em [10], para poder atender as
ONUs que operam apenas com um $\lambda$ (não-WDM). Integramos ao algoritmo IPACT a programação dinâmica de comprimento de onda. Portanto, um $\lambda$ pode ser alocado para as ONUs WDM se satisfaz a condição

$$
t_{\lambda i} \leq t_{\text {atual }}+R T T+t_{g}+t_{s},
$$

na qual, $t_{\lambda i}$ é o instante em que o $\lambda i$ será liberado; $t_{\text {atual }}$ é o tempo atual; RTT é o intervalo de ida e volta até uma determinada ONU; $t_{g}$ é o tempo de guarda que a ONU precisa para efetuar o processamento e $t_{s}$ é o intervalo necessário para a sintonização do transmissor $\left(t_{s}=0\right.$, para ONUs com conjunto de transceptores fixos).

O diagrama de fluxo do algoritmo que determina o $\lambda$ a ser utilizado na transmissão segundo o tipo de ONU é mostrado na Fig. 5. Este algoritmo é integrado ao IPACT no OLT (programação inter-ONU). O OLT alocará um $\lambda$ que preferencialmente esteja livre no instante em que deve começar a transmissão uma determinada ONU WDM, ou aquele que seja desocupado primeiro. As ONUs não-WDM serão atendidas no respectivo canal de operação.

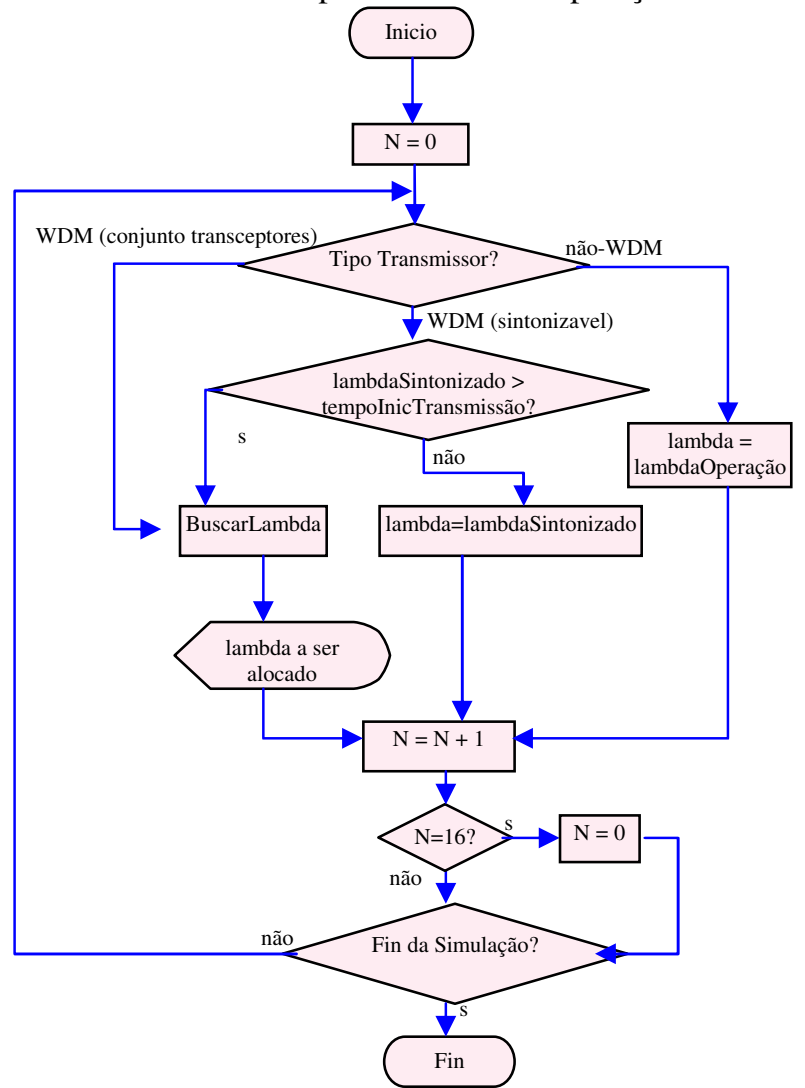

Fig. 5. Diagrama de fluxo do algoritmo que determina o $\lambda$ ótimo para a transmissão de uma determinada ONU (N é o número de ONUs).

Para efetuar esta programação, o OLT deve atualizar constantemente o instante em que cada $\lambda$ será desocupado. Isto será possível, já que o OLT conhece exatamente quando começa e termina a transmissão de cada ONU. Portanto, para determinar exatamente quando um canal será liberado é utilizada a expressão

$$
t_{\lambda i}=t_{i}^{j}+R T T_{v}+W S / R_{N}+B
$$

na qual $t_{\lambda i}$ é o instante em que será liberado o $\lambda i ; t_{i}^{j}$ é o instante em que começa a transmissão da ONU $j$ no $\lambda i ; R T T_{v}$ é o intervalo de tempo da transmissão da ONU para o OLT; $W S$ é o timeslot atribuído à $\mathrm{ONU} ; R_{N}$ é a taxa suportada pela 
fibra; $B$ é o tempo de guarda em que o OLT se preparará para receber a próxima transmissão.

\section{TDM/WDM IPACT ESTENDIDO PARA CLASSES DE SERVIÇO}

Para integrar as técnicas de suporte a classes de serviços ao esquema proposto TDM/WDM IPACT, utilizamos o método descrito em III.B [7]. Neste esquema, o OLT adiciona aos timeslots um crédito para o tráfego de prioridade alta, que é mais sensível ao atraso. A Fig. 6 mostra como é realizada a programação de prioridade nas ONUs para transmitir no timeslot alocado. O tráfego será modelado da seguinte forma:

1. Classe alta: é a classe do envio imediato (expedited forwarding-EF), que é sensível ao atraso e requer largura de banda garantida. Este tráfego é de taxa de bits constante (CBR), sendo os quadros, de 24 bytes, gerados a cada $125 \mu$ s. Incluídos os cabeçalhos Ethernet e UDP/IP resulta em 70 bytes, utilizando uma largura de banda de 4,48 Mbps.

2. Classe média: é a classe de envio assegurado (assured forwarding-AF), que não é tão sensível ao atraso e necessita largura de banda garantida. Este tipo de tráfego são as rajadas de vídeo VBR (variable bit rate).

3. Classe baixa (best effort-BE): esta classe não é sensível ao atraso e não requer largura de banda garantida. Utilizado para a transmissão de dados que não são gerados em tempo real. Empregamos tráfego auto-similar para sua simulação.

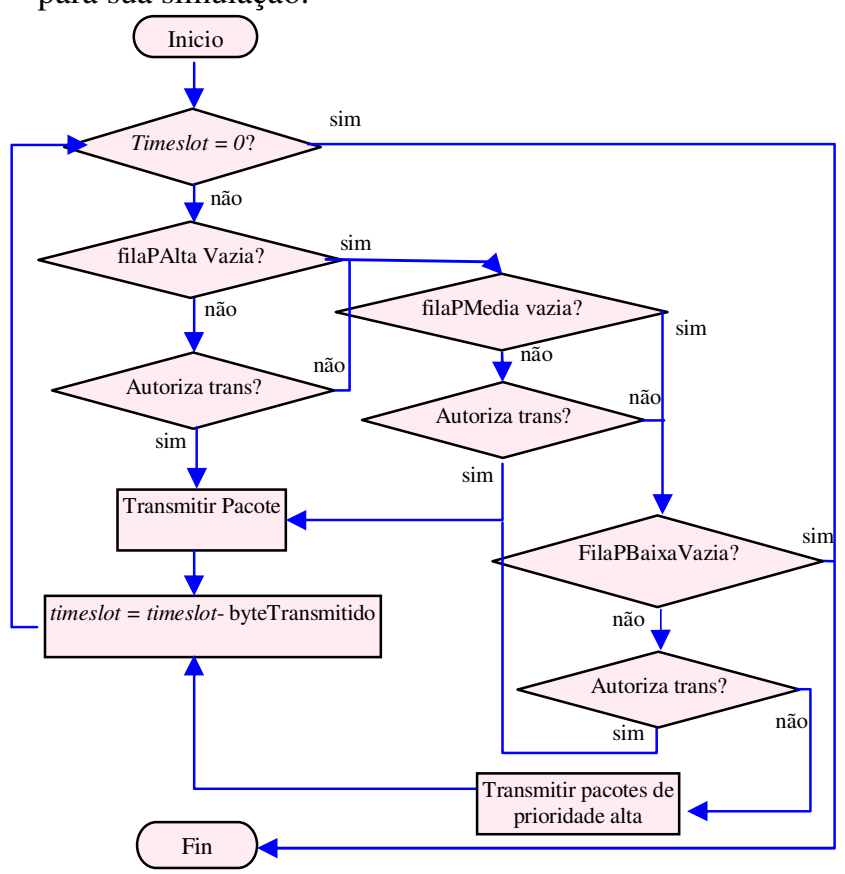

Fig. 6. Diagrama de fluxo da programação das transmissões efetuada na ONU.

A Fig. 7 mostra um exemplo de rede EPON operando com dois $\lambda$ s tanto downstream quanto upstream e quatro ONUs, as ONUs 3 e 4 operam em todos os $\lambda$ s e ONUs 1 e 2 , somente em um $\lambda(\lambda 1)$. As ONUs 1 e 2 estarão restritas a operar apenas em $\lambda 1$, tendo sempre que aguardar a que ele seja liberado. As ONUs 3 e 4 poderão operar em qualquer um dos $\lambda$ s. Assim, a ONU3 transmite quase simultaneamente com ONU1, já que $\lambda 2$ está livre nesse instante. A ONU2 transmite em $\lambda 1$ depois da ONU1 e a ONU4 transmite em $\lambda 2$ porque ele é liberado primeiro. As ONUs transmitirão, no instante agendado, os quadros das diferentes filas, conforme o diagrama de fluxo da Fig.6.

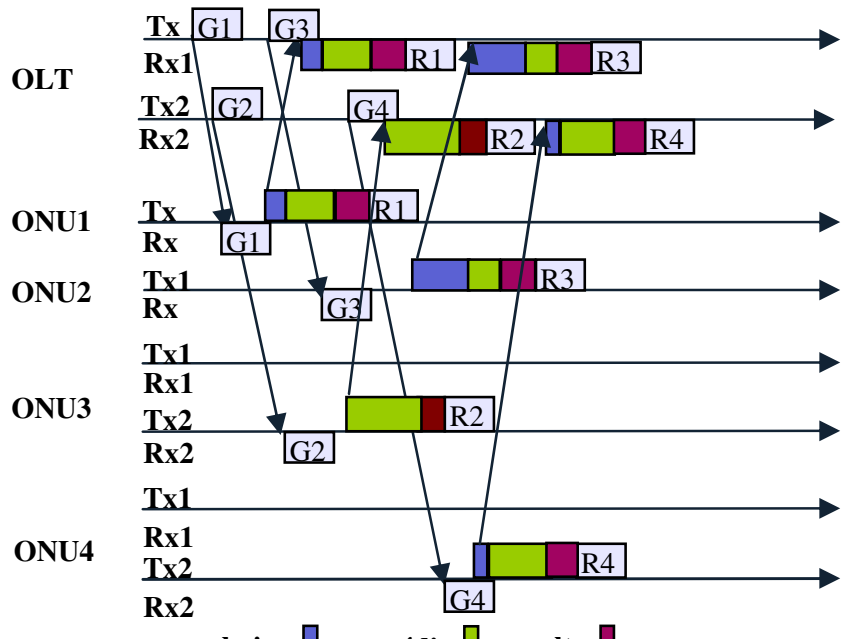

Prioridades: baixa $\square$ média $\square$ alta $\square$

Fig. 7. Sondagem intercalada operando com dois $\lambda \mathrm{s}$ e as ONUs dando suporte a classes de serviço $\left(\mathrm{T}_{\mathrm{x}}\right.$ Transmissor, $\mathrm{R}_{\mathrm{x}}$ Receptor).

\section{RESUlTADOS NumÉRICOS}

\section{A. Parâmetros de Entrada para a Simulação}

Para a simulação foram utilizados os parâmetros mostrados na Tabela I.

TABELA I

PARÂMETROS DE SIMULAČ̃o

\begin{tabular}{clc}
\multicolumn{3}{c}{ PARÂMETROS DE SIMULAÇÃO } \\
\hline Símbolo & \multicolumn{1}{c}{ Descrição } & Valor \\
\hline$R_{u}$ & Taxa do canal (usuários-ONUs) & $100-300 \mathrm{Mbps}$ \\
$R_{N}$ & Taxa do canal da EPON & $1 \mathrm{Gbps}$ \\
$N$ & Número total de ONUs & $16 / 32$ \\
$O_{W D M}$ & Número de ONUs WDM & $8 / 16$ \\
$n$ & Número de classes de prioridade & 3 \\
$Q$ & Tamanho do buffer nas ONUs & $10 \mathrm{MB}$ \\
$L$ & Distância máxima entre OLT e ONUs & $20 \mathrm{~km}$ \\
$W_{M A X}$ & Máximo tamanho do timeslot & $15000 \mathrm{~B}$ \\
$B$ & Tempo de guarda entre transmissões & $5 \mu \mathrm{s}$ \\
$T_{M A X}$ & Tempo máximo do ciclo de sondagem & $2 \mathrm{~ms}$ \\
$t_{s}$ & Tempo de sintonização do transmissor & $5 \mathrm{~ns}$ \\
$t_{g}$ & Tempo de guarda nas ONUs & $5 \mu \mathrm{s}$ \\
$R T T$ & Intervalo de ida e volta da ONU-OLT & $100-200 \mu \mathrm{s}$ \\
\hline
\end{tabular}

\section{B. Esquema TDM/WDM IPACT}

Para as simulações, consideramos que o sistema é formado por N ONUs, das quais metade é não-WDM e a metade restante, WDM. As ONUs WDM operam em todos os comprimentos de onda suportados pela rede e são submetidas ao dobro do tráfego das ONUs não-WDM. Quando o sistema esta operando com apenas um $\lambda$, consideramos que todas as ONUs são não-WDM. Cada $\lambda$ suporta $1 \mathrm{Gbps}$. O tráfego gerado é do tipo Poissoniano, assim o tamanho do quadro e os intervalos entre as chegadas seguem distribuição exponencial. Os resultados da simulação são mostrados em forma de atraso médio do quadro em função da carga total do sistema. Esta carga total (Gbps) é o resultado da soma de todas as cargas experimentadas pelas ONUs.

A Fig. 8 apresenta os resultados da simulação da EPON com 16 ONUs, na qual a carga das ONUs não-WDM é variada de $10 \mathrm{Mbps}$ até $120 \mathrm{Mbps}$ e as ONUs WDM de 
$20 \mathrm{Mbps}$ até $240 \mathrm{Mbps}$. Pode-se observar que, conforme aumenta o número de $\lambda \mathrm{s}$, o atraso do quadro diminui significativamente. Porém, quando o sistema esta operando com $4 \lambda \mathrm{s}$, a diminuição do atraso é mínima. Isto ocorre por que a taxa garantida das ONUs não-WDM (118 Mbps) foi atingida. A partir da qual, essas ONUs experimentaram maiores atrasos, comprometendo a estabilidade da rede. Portanto, é necessário limitar a taxa máxima de operação dessas ONUs.

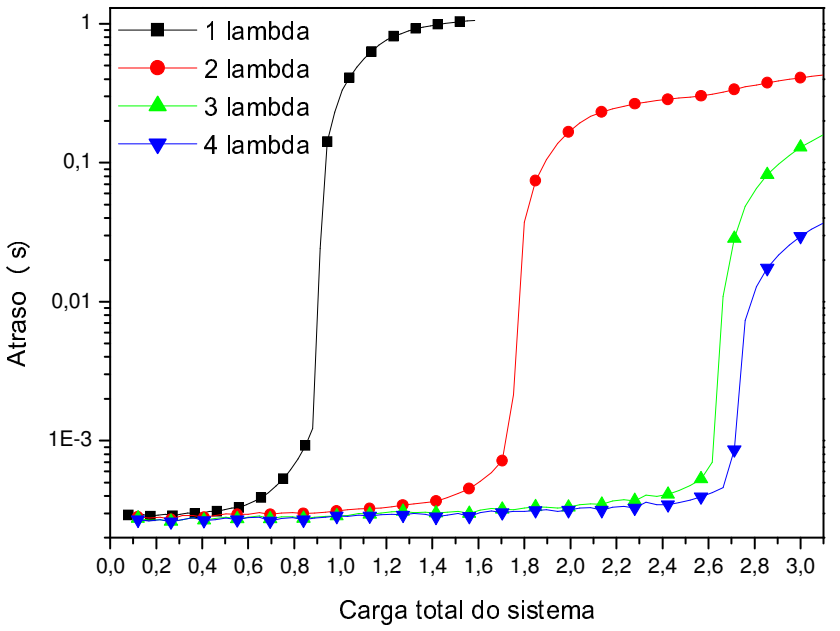

Fig. 8. Atraso de quadro versus número de $\lambda$ s utilizado na EPON com 16 ONUs.

A Fig. 9 mostra a simulação da EPON com 32 ONUs. Pode-se observar que, quando a capacidade máxima de um canal é atingida, a adição de um novo $\lambda$ diminui significativamente o atraso experimentado. Porém, quando a carga total do sistema é aproximadamente $2,8 \mathrm{Gbps}$, as ONUs WDM experimentam uma carga de aproximadamente 116 Mbps e as ONUs não-WDM, 58 Mbps. Como as ONUs não-WDM compartilham somente um $\lambda$ para a transmissão, a sua taxa garantida, $60 \mathrm{Mbps}$ [8], é praticamente atingida. Portanto, a partir do $\lambda 4$ se observam valores similares para o atraso do quadro, entre 2,8 Gbps e 4 Gbps. Este atraso pode ser diminuído mediante a atualização de algumas ONUs não-WDM para WDM. Porém, as ONUs WDM podem operar apresentando cargas maiores.

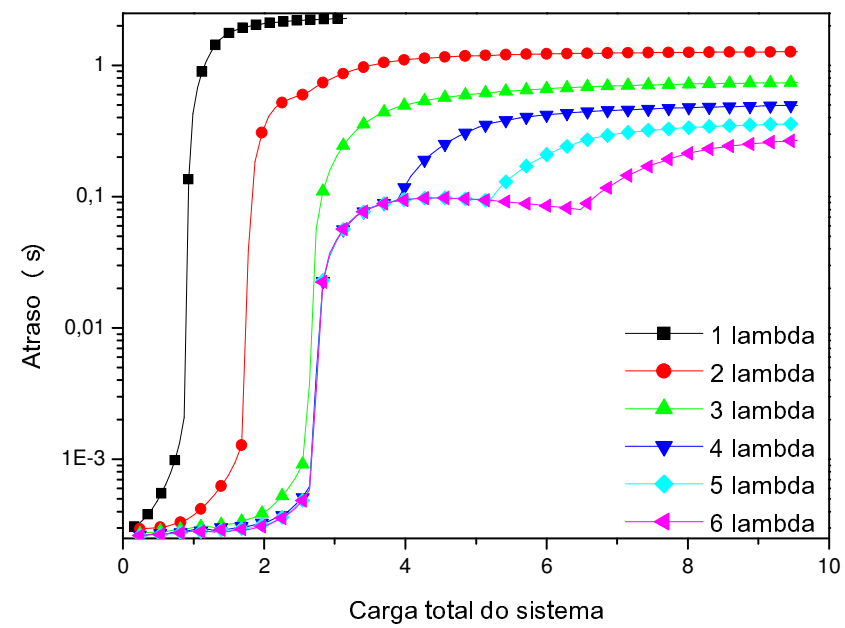

Fig. 9. Atraso do quadro versus número de $\lambda$ utilizado na EPON com 32 ONUs.

\section{Esquema TDM/WDM IPACT Estendido para Classes de Serviço}

Nas simulações consideramos a EPON constituída de 16 ONUS. Igualmente, a metade é WDM e a outra metade é não WDM. Cada tipo de tráfego experimenta a seguinte carga: (1) prioridade alta apresenta um tráfego constante de 4Mbps; (2) prioridades média e baixa apresentam uma carga igual a

$$
R_{T}=\left(R_{\text {atual }}-4 M b p s\right) / 2
$$

na qual $R_{\text {atual }}$ é o tráfego experimentado na ONU num determinado instante.

Utilizamos modelo de tráfego auto-similar para sua simulação porque representam melhor a situação real do tráfego em rajada das redes Ethernet [8]. Segundo ele, se uma conexão está ativa, ela tende a permanecer nesta condição. As rajadas foram geradas utilizando a distribuição Pareto limitada e os intervalos entre as rajadas são gerados utilizando a distribuição exponencial. Foi utilizado o parâmetro de forma $\alpha=1,4$ [14] e os valores mínimo e máximo para a rajada são 1 e 100000 , respectivamente.

Os resultados da simulação deste esquema, operando com apenas um $\lambda$, são mostrado na Fig. 10. Eles são concordantes com os obtidos em [7]. Pode-se observar que o atraso máximo experimentado pelo tráfego de prioridade alta é $1 \mathrm{~ms}$ e o atraso máximo do tráfego de prioridade média alcança $4 \mathrm{~ms}$ para uma taxa de transmissão de aproximadamente $48 \mathrm{Mbps}$ para ambas. Porém, o tráfego de prioridade baixa, que apresenta a mesma taxa que o tráfego de prioridade média, experimenta um atraso maior, de até 1,55 s. A razão é que o tráfego de prioridade média é sempre atendido antes que o tráfego de prioridade baixa. O tráfego de prioridade baixa é atendido unicamente com o restante da largura de banda atribuída. $\mathrm{O}$ tráfego de prioridade média experimentará um aumento significativo no atraso, com taxa de aproximadamente $55 \mathrm{Mbps}$, porque o sistema está projetado para garantir uma taxa de $60 \mathrm{Mbps}$.

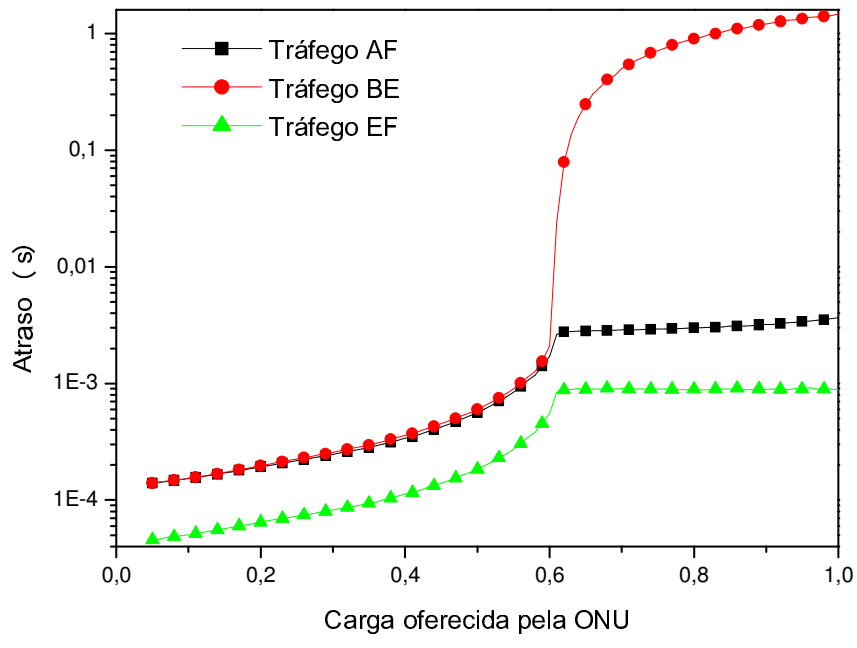

Fig. 10. Atraso médio do quadro para os tráfegos de prioridade alta (EF), média (AF) e baixa (BE) com a EPON operando com dois $\lambda \mathrm{s}$.

Nas simulações a seguir consideramos 8 ONUs WDM e as restantes não-WDM. As ONUs WDM são submetidas ao dobro da carga (tráfegos de prioridade média e baixa) das ONUs não-WDM.

A Fig. 11 apresenta os resultados para o atraso médio do 
quadro utilizando dois $\lambda$ s. Neste gráfico se observa uma diminuição significativa do atraso experimentado pelos quadros dos três tipos de prioridade, em comparação aos resultados do esquema utilizando único $\lambda$ (Fig. 10). O atraso máximo da classe alta diminuiu de aproximadamente $1 \mathrm{~ms}$ para 0,4 ms. De forma semelhante, o atraso dos quadros de prioridade média e baixa diminuiu de aproximadamente $4 \mathrm{~ms}$ para 1,5 ms e de 1,55 s para 0,55 s, respectivamente. Assim mesmo, o máximo atraso experimentado pelo tráfego de prioridade alta foi deslocado para uma carga total do sistema de aproximadamente 2,2 Gbps.

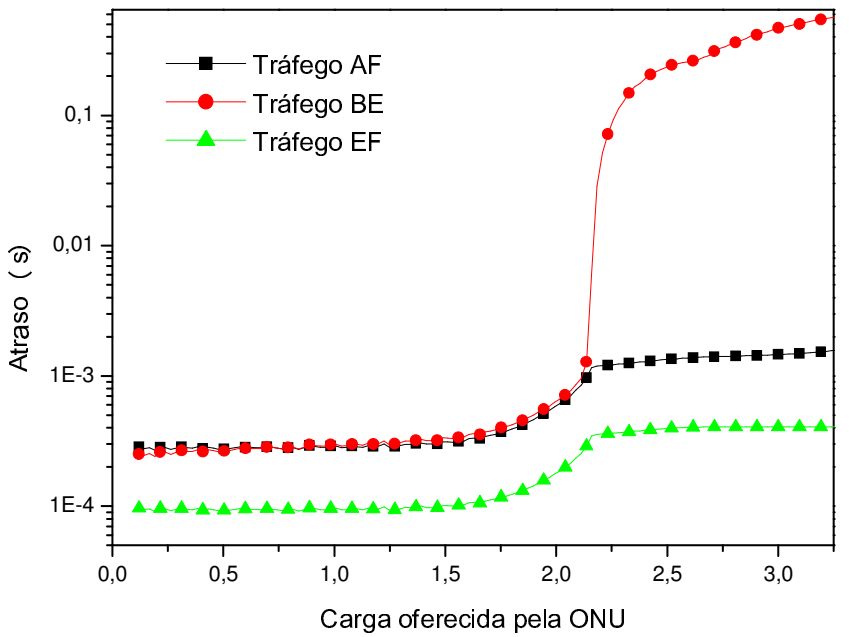

Fig. 11. Atraso médio do quadro para os tráfegos de prioridade alta (EF), média $(\mathrm{AF})$ e baixa (BE) utilizando dois $\lambda \mathrm{s}$.

A Fig. 12 apresenta o atraso médio do quadro da EPON operando com três $\lambda \mathrm{s}$. De maneira similar pode-se observar que os atrasos experimentados pelos quadros de todas as prioridades diminuem em relação à EPON operando com dois $\lambda$ s. $\mathrm{O}$ atraso máximo do tráfego de prioridade alta é diminuído de 0,4 ms para 0,2 ms e do tráfego de prioridade média e baixa de $1,5 \mathrm{~ms}$ para $0,97 \mathrm{~ms}$ e $0,55 \mathrm{~s}$ para $0,15 \mathrm{~s}$, respectivamente. $\mathrm{O}$ atraso máximo do tráfego de prioridade alta foi deslocado para uma carga total do sistema de aproximadamente 3 Gbps.

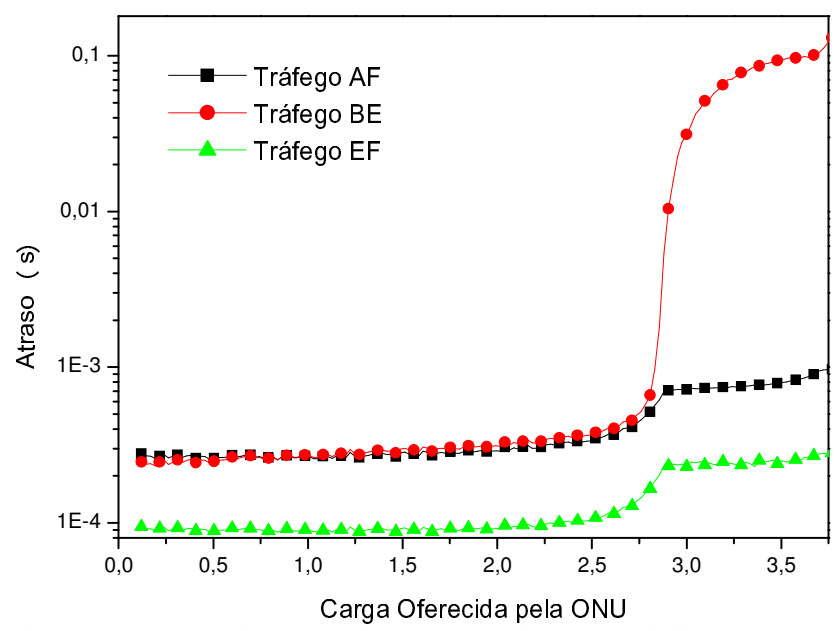

Fig. 12. Atraso médio do quadro para os tráfegos de prioridade alta (EF), média (AF) e baixa (BE) utilizando três $\lambda \mathrm{s}$.

\section{CONCLUSÕES}

Neste trabalho, redes EPON operando com três tipos de ONUs foram simuladas. Esta abordagem não havia sido considerada na literatura. Para realizar as simulações fizemos uma modificação no algoritmo proposto em [10]. Os resultados mostraram a diminuição do atraso cada vez que um novo $\lambda$ de operação foi adicionado. Porém, as ONUs não-WDM sempre estarão limitadas pela taxa garantida, calculada em função do número de ONUs deste tipo. Esta largura de banda garantida pode ser aumentada cada vez que uma ONU não-WDM é atualizada para WDM. Desta forma, se disponibiliza maior taxa garantida para as ONUs nãoWDM e, portanto, o atraso experimentado pelos seus quadros diminui. Também foram integradas com bom desempenho as técnicas de suporte a classes de serviço ao esquema WDM IPACT. Os resultados mostraram que as ONUs podem aumentar sua carga, tendo sempre um controle sob os tipos de tráfego sensíveis ao atraso, até diminuindo significativamente o atraso experimentado por estes, especialmente para cargas altas, já que são priorizados para a transmissão em cada canal.

\section{REFERÊNCIAS}

[1] Maode Ma, Yongqing Zhu and Tee Hiang Cheng, "A Bandwidth Guaranteed Polling MAC Protocol for Ethernet Passive Optical Networks", INFOCOM 2003, Twenty-Second Annual Joint Conference of the IEEE Computer and Communications Societies, vol. 1, pp. 22-31, abril 2003.

[2] Ton Koonen, "Fiber to the home/fiber to the premises: What, Where, and When?", Proceedings of the IEEE, vol. 94, No 5, pp. 911-934, maio 2006.

[3] Paul E. Green, "Fiber to the home: The Next Big Broadband Thing", IEEE Communications Magazine, vol. 42, $\mathrm{N}^{\circ} 100-106$, setembro 2004.

[4] Glen Kramer and Gerry Pesavento, "Ethernet Passive Optical Network (EPON): Building a Next-Generation Optical Access Network", IEEE Communications Magazine, vol. 40, pp. 66-73, fevereiro 2002.

[5] Michael P. McGarry, Martin Maier, and Martin Reisslein, "Ethernet PONs: A Survey of Dynamic Bandwidth Allocation (DBA) Algorithms", IEEE Communications Magazine, vol.42, agosto 2004.

[6] IEEE 802.3ah, Ethernet in the First Mile Task Force, http://www.ieee802.org/3/efm/index.html.

[7] Glen Kramer, Biswanath Mukherjee, Sudhir Dixit, Yinghua Ye "Supporting differentiated classes of service in Ethernet passive optical networks", Journal of Optical Networking, vol. 1, № 8 \& 9, agosto \& setembro 2002.

[8] Glen Kramer, Biswanath Mukherjee and Davis Gerry Pesavento, "IPACT: A Dynamic Protocol for an Ethernet PON (EPON)", IEEE Communications Magazine, vol. 40, № 2, pp. 74-80, fevereiro 2002.

[9] Kae Hsiang Kwong, David Harle and Ivan Andonovic, "Dynamic Bandwith Allocation Algorithm for Differentiated Services over WDM EPONs", Communication Systems, ICCS 2004, The Ninth International Conference on, pp. 116-120, 6-8 setembro 2004.

[10] Michael P. McGarry, Martin Maier and Martin Reisslein, "An Evolutionary WDM Upgrade for EPONs", http://www.fulton.asu.edu/ mre/EPONupgrade.pdf (data de acesso maio 2007).

[11] Michael P. MacGarry, Martin Reisslen and Martin Maier, "WDM Ethernet Passive Optical Networks", IEEE Optical Communications Magazine, vol. 44, № 2, pp. 15-22, fevereiro 2006.

[12] Ahmad R. Dhaini, Chadi M. Assi and Abdallah Shami, "Dynamic Bandwidth Allocation Schemes in Hybrid TDM/WDM Passive Optical Networks", IEEE $3^{\text {rd }}$ Networking Conference CCNC, vol. 1 , pp. 30-34, janeiro 2006.

[13] Glen Kramer, Ethernet Passive Optical Networks, McGraw-Hill, United State of America, 2005.

[14] Will E. Leland, Murad S. Taqqu and Daniel V. Wilson "On the selfsimilar Nature of Ethernet Traffic (Extended Version)", IEEE/ACM Transaction on Networking, vol. 2, No 1, pp. 1-15, fevereiro 1994. 